\section{Palofra}

acceso $\partial$ abierto

Cómo citar: Segura, J. (2020). Con el deseo en la boca: Sexo, poder y subjetividad en hombres que tiene sexo con hombres. Palobra, 20(1), 113-125. https://doi.org/10.32997/23462884-vol.20-num.1-2020-3228

Recibido: 22 de marzo de 2020.

Aprobado: 2 de mayo de 2020.

Editora: Rosario Blanco Bello. Universidad de Cartagena-Colombia.

Tipología IBN Publindex:

Artículo de Reflexión.

\title{
Con el deseo en la boca: Sexo, poder y subjetividad en hombres que tienen sexo con hombres ${ }^{1}$
}

\author{
With desire in the mouth: Sex, power and subjectivity in men who \\ have sex with men
}

José Miguel Segura Gutiérrez

Universidad Cooperativa de Colombia-Colombia,jose.segurag@campusucc.edu.co.josemielsegura@gmail.com

\section{RESUMEN}

Este artículo aborda la forma en que el sexo oral como práctica sexual, configura el establecimiento de subjetividades y relaciones estratégicas de poder, entre hombres que tienen sexo con hombres (HSH), además de discutir el enganche que el dispositivo de sexualidad con sus cuerpos y placeres tiene para con el alcance de una vida buena por parte de tales sujetos. Concluye que este tipo de práctica sexual, aunque no es una marca distintiva en la dinámica sexual ejecutada por dicho colectivo sociosexual, sí podría configurarse como factor de riesgo para la salud de quienes la practican, cuando no se consideran aspectos de higiene, cuidado de sí mismo y del otro.

Palabras clave: Placer; cuerpo; HSH; conductas de riesgo; sexualidad.

\begin{abstract}
This article addresses the way oral sex as a sexual practice, configures the establishment of subjectivities and strategic power relations, between men who have sex with men $(\mathrm{HSH})$, in addition to discussing the attachment that the device of sexuality with their bodies and pleasures has with the reach of a good life on the part of such subjects. Concludes that this type of sexual practice, although it is not a distinguishing mark in the sexual dynamics performed by such a socio-sexual group, could be configured as a risk factor for the health of those who practice it, when hygiene aspects are not considered, taking care of himself and the other.
\end{abstract}

Keywords: Pleasure; body; MSM; risky behaviors; sexuality.

Copyright: () 2020. Segura, J. Este es un artículo de acceso abierto, distribuido bajo los términos de la licencia https://creativecommons.org/licenses/by-nc$\mathrm{sa} / 4.0 /$ la cual permite el uso sin restricciones, distribución y reproducción en cualquier medio, siempre y cuando que el original, el autor y la fuente sean acreditados.

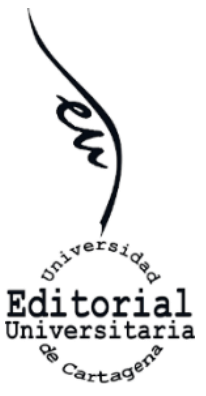

\footnotetext{
${ }^{1}$ El presente artículo es producto de trabajo integrador del autor como investigador en temas de sexualidad, ciudad y educación; y catedrático del área de Humanidades en la Universidad Cooperativa de Colombia (Seccional Villavicencio). El desarrollo de este tex to no recibió financiamiento específico.
} 
Por la trama del código transitan los sujetos, no en tanto identidades individualizadas, definidas, conscientes, sino como viajeros a la deriva, en la multiplicidad de los flujos deseantes, en el azar y la instantaneidad de los encuentros (Néstor Perlongher, 1993, p. 103).

\section{INTRODUCCIÓN}

En los últimos años el incremento de los casos de infecciones de transmisión sexual, han estado asociados al número de compañeros sexuales tanto en parejas heterosexuales como en hombres que tienen sexo con hombres (HSH) (Viscarrra et al., 2013), así como a cambios en el comportamiento sexual y social suscitados por el acelerado proceso de urbanización y la creciente precocidad y promiscuidad sexual de los sujetos (Cortés et al., 2000). Sin embargo, las infecciones en ambos grupos poblacionales, han sido trasmitidas vía sexo anal u oral, como producto del no uso del condón, favoreciendo la transmisión de patógenos presentes en el semen al compañero sexual. Esto, dada las condiciones óptimas que dicho fluido presenta para la supervivencia de bacterias y virus, y que en suma pueden generar no solo la pérdida de vitalidad de los espermatozoides (Chlamydia trachomatis), sino también la infertilidad en el hombre al reducir la calidad del semen y el potencial de fertilización del espermatozoide (Mollicutes). Lo anterior, sin dejar de mencionar la sífilis, una lesión de tipo primaria facilitadora de la adquisición y transmisión del virus de inmunodeficiencia humana (VIH), y cuya principal vía de trasmisión es el semen, como producto de la presencia de la bacteria Treponema Palladium.

No obstante, a estas infecciones de transmisión sexual, se suma el virus del papiloma humano VPH, una infección de transmisión sexual ITS que en hombres ha sido asociada de manera puntual con lesiones (verrugas) anogenitales y cáncer de pene, pero que en HSH y VIH positivos, aumenta su riesgo de infección con VPH (Hinojos-Armendáriz et al. 2016). Esto en razón, a factores tales como edad, estado civil, nivel de escolaridad, tipo de ocupación, edad de inicio de la vida sexual, orientación sexual, número de compañeros sexuales, diagnóstico de VIH, presencia de úlceras, verrugas y flujos anormales (Hinojos-Armendáriz et al. 2016).

Un conjunto de afectaciones sobre el cuerpo y la salud, que a escala mundial presenta, un aumento en la prevalencia de ITS y cuyo origen radica en la ejecución de prácticas sexuales que involucran el ano y la boca, pero que en la práctica del sexo oral ejecutado por parejas heterosexuales y entre $\mathrm{HSH}$, resulta de mayor riesgo para la infección por VIH, si el semen o líquido preseminal llega a la boca y en ella existen vías de conexión con el flujo sanguíneo como lo pueden ser llagas o heridas, la saliva no tiene capacidad de transmisión del VIH, dada su contenido de proteínas y bajo nivel de sal. "[...] desde que el virus se ha hecho visible en la agenda pública se le ha vinculado con ciertos grupos poblacionales, dentro de los que sobresale el de hombres que tienen relaciones sexuales con otros hombres (HSH)" 
(ONUSIDA, 2017), grupo entre el cual se estima una prevalencia de la infección en Latinoamérica que oscila entre el 5 y el 40 \% (Estrada y Vargas, 2011); y para el caso de Medellín se tiene una prevalencia del 20,7 \% para 2015 (Mecanismo de Coordinación de País - MCP Colombia Fondo Mundial de Lucha contra el Sida, la Tuberculosis y la Malaria, 2016), dando cuenta de una concentración de la infección por VIH en este grupo poblacional.

Panorámica que no solo visibiliza un problema de salud pública, sino que también muestra la vinculación a prácticas sexuales de riesgo por ejemplo que el 18,5 \% de los HSH refirió utilización del condón solo algunas veces y el 2,8 \% reportó que nunca lo usa; por otra parte, también se evidenció que la discriminación hace fuerte presencia en la vida de los HSH: el 22,2 \% de participantes reportaron rechazo, desprecio u ofensa familiar frente a su orientación sexual y el $12,1 \%$ teme que información sobre su vida sexual quede registrada en su historia clínica (MCP Colombia Fondo Mundial de Lucha contra el Sida, la Tuberculosis y la Malaria, 2016).

Situaciones, que sin duda invitan a gestionar acciones preventivas desde la(s) persona(s) que adelanta(n) este tipo de prácticas de riesgo y que, para el caso de la práctica del sexo oral, podrían partir de la higiene bucal de quien lo practica y la observación detallada a los habituales problemas de encías, uso del preservativo y solicitud al compañero sexual, de los resultados de su prueba de VIH. Aspectos que requieren de conocimientos puntuales sobre sexualidad, desde la arista salud-prevención, según Cardona et al., (2015) "[...] los varones tienen mayor desconocimiento con relación a las infecciones de transmisión sexual y su prevención”, así como del desarrollo de estrategias de cuidado y autocuidado del cuerpo y la salud. Además, Marín y Posada (2020) afirman que " [...] en el terreno de pareja es posible perder los límites, y allí es cuando bajo la égida del amor se presenta una "entrega total" que desdibuja la implementación de prácticas de cuidado" (p.21). Y termina por exponer a uno de los dos al riesgo.

La práctica del sexo encripta y despliega un entramado de relaciones jerárquicas que hacen tanto de heterosexuales como de los HSH sujetos vulnerables a prácticas sexuales de riesgo (comportamientos que promueven una afectación en la persona que las realiza) vehiculizadas por el bajo uso del condón y que en el marco de la aparición de las terapias de tratamiento antirretroviral hizo por ejemplo que el VIH deviniera en enfermedad crónica, esto sin desestimar la presencia de un paisaje en donde los modos de relacionarse promiscuos y por fuera del relato del amor romántico, han terminado por afectar la dimensión subjetiva de tales sujetos. Lo que se privilegia en la contemporaneidad aunque no de forma generalizada es la obtención de placer vía sexo sin compromiso ${ }^{2}$.

${ }^{2}$ El Sexo Sin Compromiso (SSC) lo entiendo como una práctica sexual que evita estrategias de involucramiento personal y de cuidado del otro, guiado por valores propios, actitudes, costumbres y creencias en torno al ejercicio de la sexualidad, goce erótico y la obtención de placer. Algunos autores lo han definido como un episodio interpersonal donde se presenta 
La prerrogativa cultural de que los hombres tienen el derecho a ejercitar su sexualidad sin responsabilizarse por quien(es) se involucra (n) con ellos, ubica a los HSH como sujetos vinculados a un pacto de silencio siempre desafiante, en donde "las ganas le pueden al miedo", y la práctica del sexo oral, termina constituyéndose en una experiencia no solo placentera y eróticamente excitante, sino también, visibilizadora del poder y seducción, que al menos uno de los dos sujetos que participan de la misma tiene como riendas en su mano y podría tirar en cualquier momento en pro de alcanzar ciertos deseos u obtener cierto tipo de prácticas y comportamientos sexuales, no distantes de los roles de género preestablecidos. Tal y como sugieren Bruckner y Finkielkraut (2001) "aunque participemos de la democracia, nuestros cuerpos siguen siendo dirigidos por un poder que se ubica en el pene y que es a su vez respaldado por los testículos". Elementos biológicos, que buscan generar pautas de acción en el ámbito sociocultural, a través del fortalecimiento al poder cultural y de supremacía de los hombres como de la masculinidad, pero que a todas luces delinean la estructuración de relaciones sociosexuales y prácticas sexuales basadas en el género, objeto de interés del presente escrito.

"La eyaculación funciona como un testimonio de placer visible" (MöllerGonzález, 2013: 59).

\section{1. ¿Quién quiere una rica verga para mamar?}

Sin duda, las relaciones sexuales orales efectuadas entre hombres que tienen sexo con hombres (HSH) como en parejas heterosexuales y homosexuales implican usar la boca, los labios o la lengua para estimular el pene (felación), ano (anilingus) o cualquier otra parte de la geografía corporal de la pareja sexual. Situación está que define no solo una toma de posición por parte del sujeto en el juego sexual, sino también, la configuración de cierto tipo de subjetividad, a partir de los usos del cuerpo. Si bien es cierto, el sexo oral y la ingesta de semen no constituye en sí mismo un patrón de deseo sexual o conducta personal anormal en los sujetos, si posee elementos culturales que justifican su reflexión como mecanismo de socialización y obtención de placer mediante el contacto físico.

Por ello, que al analizar la práctica de sexo oral ejecutada por HSH se tenga, que este tipo de experiencia otorga sentido a sus vidas, además de hacerlos protagonistas de la erotización del dominio y la sumisión por parte de otros hombres, ante el carácter genital que ha adquirido la sexualidad, como producto cultural, dentro de una época en donde lo afectivo-emocional ha sido abandonado en favor de la discreción ${ }^{3}$, y cumplimiento de deseos alojados en

intimidad física y erótica, pero sin que exista una relación romántica en el momento en que ocurre dicha cercanía, ni una expectativa mutua de un compromiso futuro (Lewis et al., 2011).

3 Según Ramírez-García (2017) esta noción hace referencia a un conjunto de características de la subjetividad sexual homoerótica, ya sea homosexual, gay, hombres que tienen sexo con otros hombres, entre otras, su núcleo sociológico gira en torno a dos dimensiones, la primera es la ocultación premeditada y consciente de su atracción y deseo por los hombres, 
la imaginativa sexual que trae el otro al encuentro. Situación que termina por reproducir el código de género, y visibilizar como: "[...] aunque todos los individuos existen dentro de los estratos de la subjetividad, también están situados en determinadas posiciones, cada una de las cuales permiten y restringen las posibilidades de la experiencia, de representar esas experiencias y de legitimar esas experiencias" (Grossberg, 2000, p. 167).

Por lo que, resulta importante distinguir dentro del conjunto de prácticas sexuales ejecutadas por HSH, aquellas experiencias y prácticas de riesgo que como hombres desarrollan en torno a lo sexual y el conjunto de relaciones sociopersonales que pueden derivarse de allí. Si bien es cierto, no son solo las prácticas de riesgo vinculadas a la clandestinidad y disociación afectiva, así como la asociación con el papel cumplido en las relaciones sexuales (receptivo-insertivo), y confianza en el desarrollo científico en el área salud acrecienta el peligro de riesgo y disminución de prácticas de cuidado y autocuidado, si resulta válido afirmar que el uso del condón es la opción médico-preventiva más inmediata para superar el contagio con ITS. Según Marín y Posada (2020):

[...] las prácticas de cuidado y de riesgo de HSH con VIH están influenciadas por un contexto relacional donde se llevan a cabo interacciones de reconocimiento y menosprecio. En esta trama la heteronormatividad es un elemento central que atraviesa los vínculos en escenarios privados (familia, amigos, pareja) y públicos (instituciones educativas, de salud, etc.); de modo que las prácticas de cuidado-riesgo merecen ser comprendidas en clave de justicia social y no sólo como aptitudes meramente individuales (p. 1).

Esto en virtud, a que todo régimen busca el gobierno de las personas y sus cuerpos, además del silenciamiento a aquello que se considera condenable y por ende debe ser invisibilizado, para mantener el orden social establecido. Es decir, aquel pacto obligado de fuerzas, que evidencia como nos debemos a otros, ya sea para paliar la soledad o evitar inundarnos a sí mismos de sufrimiento. Razón por lo cual, ya "[...] hubiera caído encima de ti como saltamontes sobre un trigal” (Fallaci, 1996, p. 24). En la configuración de la economía del deseo vinculada a las prácticas sexuales ejecutadas entre HSH y en donde se persigue la obtención de placer sexual, contar con ciertos espacios, tiempos y recursos resultan necesarios, para que el individuo pueda hacerse a un modo de vida, y desde allí, intentar comprender su propia existencia e interacción con los otros. Según Sanabria (2004) algunos de los hombres que acuden a las salas X en Medellín (Colombia), lo hacen para acceder a la compañía de hombres jóvenes con los que se espera tener sexo oral, y una pequeña cuota de placer.

la segunda es el performance continuo del sujeto que busca alejarse de la significación negativa de lo "femenino" en el orden simbólico de género. 
Una línea de fuga ante la obsolescencia de las actuales experiencias de vida, cuya luminosidad se da a través del carácter furtivo de los encuentros, la eliminación de la palabra hablada, además de la no consideración de aspectos básicos de higiene y protección durante la práctica sexual, esto sin descontar la ausencia de rostricidad. El pene, hoy es mucho más que el rostro y la imagen de quien lo porta. Por tal motivo, si se quiere hacer parte de la máquina social, tanto el cuerpo como el rostro deben alinderarse a libretos dictados por la subjetividad dominante (Rolnik y Guattari, 2006). Es decir, a las diferentes formas en que la cultura busca normalizar los sujetos, sus cuerpos y subjetividades.

Esos otros modos de vivir la sexualidad y experiencia de ser hombres han favorecido la visibilización de un conjunto de transformaciones frente a la manera en que pensamos y vivimos ciertas dimensiones de nuestra vida, además de desplegar un abanico de posibilidades éticas, en un contexto en donde "esforzándose en organizar los encuentros... no evitaremos todo mal encuentro, no evitaremos la muerte" (Deleuze, 1996, p. 253). Lo que persigue la práctica del sexo oral y en ella la ingesta de semen, no es solo animar la vida de forma creativa, sino potenciarla desde la herida masculina, es decir, de aquel quiebre corporal y psíquico en la experiencia de sí mismo y la pérdida de dominio sobre otros. Cuestión que no reduce, la percepción de riesgos.

De acuerdo con Cabra-Ayala (2017) la herida masculina es el precio que los hombres pagan como tributo por transgredir la masculinidad hegemónica. En otras palabras, por apostar a nuevas formas de vivir la masculinidad, desde la experimentación sobre aristas tales como el dolor, afecto o placer. Un placer masculino, que para el caso de los HSH se haya desprovisto de fines reproductivos, pero que es importante abordar con actitud crítica, ante los peligros de mensajes que tienden a normalizar y homogeneizar las conductas humanas en torno a cómo debe ser experimentado el placer, como lo advierte Tiefer (1995). Según Foucault (2007; 1976) la sexualidad, es un dispositivo histórico que participa de forma activa en los modos de subjetivación del sujeto y sus comportamientos sexuales, es decir, de la experiencia consciente de los actos. Su eficiencia radica en la producción de sí mismos, el dispositivo opera a través de criterios de diferencia sexual que marcan espacios y formas de relacionarse entre los cuerpos-sujetos, a partir de la codificación de conductas y normas sexuales que se empalman vía acción cultural. Por lo cual, se admite cierto matiz moral en el perfilamiento de lo que se espera de los HSH.

El placer sexual (excitación, erección y eyaculación) alcanzado a través de la ejecución del sexo oral en tanto práctica sociosexual, no solo se haya constituido de la fuerza que guía el alcance del objeto/sujeto deseado o de la satisfacción de su posesión, sino del despliegue de la seducción como proceso liberador del semen en tanto fluido corporal hegemónico. "El placer sexual 
es la satisfacción y disfrute físico y/o psicológico que se obtiene de cualquier intercambio erótico" (Philpott et al., 2006, p. 16). Para el caso de una práctica sexual que de acuerdo con Epícuro (1997) debiera implicar garantías de no daño o el desarrollo de sentimientos morales negativos. Es un acto libre y liberador, que otorga diferenciación con respecto al sentido que damos a la vida.

Las diferentes disposiciones eróticas que articula el semen, lo que hacen es representar un poder material y simbólico, cuya primera visualización está dada por la identificación de una vida, sumada al favorecimiento del contacto interpersonal entre aquellos hombres que lo han sublimado, para luego, avanzar hacia situaciones de proximidad corporal, que requieren del establecimiento de jerarquías y negociación para posibilitar el/los encuentro(s) sexual(es), no siempre ausentes de ternura, pero si firmes en su propósito de recibir la cálida simiente dentro de márgenes de silencio y espacios para la fabricación de placer. "El placer es el único medio con que cuenta un sujeto para reconstituirse ante un episodio que lo desborda" (Deleuze, 1995, p.13-14).

Se trata, de un intento de recomponer el cuerpo/sujeto/objeto de los $\mathrm{HSH}$, a través del devenir de nuevos agenciamientos dentro de un contexto en donde los libretos sexuales han definido el significado del sexo a nivel intra e interpersonal, así como la forma en que deben darse los encuentros sexuales (masturbaciones mutuas, sexo oral, toques, caricias), lo que cuenta es "pasarla bien", sin preocuparse de los riesgos que pueda traer el sostenimiento de dicha práctica sexual cuando no se hace uso del preservativo o actúa bajo el efecto de alcohol u otras drogas. Son los mismos sujetos sexuales quienes asignan significado a las diferentes recomendaciones y prácticas preventivas y de riesgo, con base en sus contextos y las características de los encuentros sexuales (Barreda, 2006).

Por tanto, abordar el placer desde su trasgresión a las restricciones impuestas a la sexualidad, y en él al sexo oral en tanto actividad sexual, amerite considerar los riesgos que trae dicha práctica, hoy vinculada con la pandemia del VIH y el aumento de la prevalencia de infecciones de transmisión sexual (ITS) -sífilis, gonorrea, herpes genital y papilomas-. Según el Grupo de Trabajo sobre Tratamientos del VIH de Cataluña (España):

El mayor riesgo de trasmitir el VIH a través del sexo oral es si se padece alguna enfermedad de trasmisión sexual y no se ha curado o no ha sido tratada debidamente. Otra de las formas de trasmisión del VIH a través del sexo oral es si existen heridas abiertas, llagas o abrasiones en la boca o en las encías o si se tiene alguna infección, incluidas las enfermedades de trasmisión sexual, en la garganta o la boca las cuales pueden causar inflamación (Infovihtal \#15 sexo oral). 
Para reducir las conductas sexuales de riesgo, se sugiere preguntar por el estado de VIH, la fecha del último análisis, además de reducir el número de parejas sexuales con las que se mantiene sexo oral e involucrar el uso del preservativo. Lo anterior, sin dejar de mencionar la verificación de las condiciones de salud oral y la discusión en torno a no eyacular en la boca del compañero o que eyaculen en tú boca. Incluso, cuando la palabra proyectada en cada encuentro sexual se ha vaciado y olvidado al instante, sobre ella prevalece el valor comunicativo de los movimientos y roces que se ejecutan con el cuerpo. Un cuerpo ajustado a criterios estéticos y cargado de signos y marcas de virilidad como lo puede ser la dotación de un buen miembro viril.

Interpretación que contrasta de forma afirmativa con lo planteado por Perlongher (1993) en el sentido que:

(...) los otros no son vistos en cuanto 'identidades personales', sino apenas como posibilidades de un contacto parcial, órgano a órgano. El cuerpo es parcelado, ciertas partes son 'separadas' del conjunto. El objeto destacado es sobre todo el pene [...] Sería preciso, entonces, restaurar las potencias de la errancia (dejar de ver, por ejemplo, 'identidades sociosexuales", donde lo que hay son desplazamientos y flujos, territoriales y libidinales) (p. 80).

Realidad que requiere de la activación de cierta reflexividad frente a la forma en que nos aproximamos al cuerpo, sin que, por ello se limite el alcance del placer. Nos movemos a través del cuerpo, dentro de ordenes sociales que estructuran posibilidades para el contacto sexual y favorecen el estudio de los usos asignados al cuerpo en la obtención de placer y goce. A manera de ejemplo, el riesgo de contagio por VIH, y su trasmisión está determinada por conductas concretas, que incluyen relaciones sexuales sin protección, situándose el riesgo en las prácticas que ejecutan los individuos y sus estilos de vida. La posibilidad de adquirir la infección se circunscribe al ámbito de la responsabilidad individual y capacidad del individuo para autocontrolarse y evitar aquello que lo pone en riesgo (Suárez et al., 2008). En últimas, la decisión propia o consensuada de adelantar encuentros sexuales sin protección, no solo evidencia la apropiación de la noción de ética del cuidado por parte de un individuo en relación con su compañero sexual u otro agente humano, sino también su capacidad para elegir y maniobrar ante diferentes estilos de vida, que se le ofrecen y con los cuales puede alternar.

Utilizar la cavidad oral en prácticas sexuales, o simplemente olvidar el uso del condón a la hora de sostener relaciones sexuales puede conllevar a la adquisición de ITS, cuyas manifestaciones en la cavidad bucal, se caracterizan por la presencia de lesiones ulcerativas, especialmente en bordes linguales (sífilis secundaria), que pueden agravarse en su etapa tardía causando la perforación del paladar duro que comunica la cavidad nasal con la oral. (Nieto, Larrea et al., 2012). También el VPH puede desarrollar neoplasias extracervicales, tales como cáncer de pene, ano, en especial en 
orofaringe (cavidad nasal y cavidad bucal), así como la presencia de verrugas y vegetaciones de color violeta y blanco en caras dorsal y ventral de lengua. Lesiones generalmente asintomáticas, y relacionadas con prácticas sexuales oro-genitales (Carmona-Lorduy et al., 2018). La boca actúa como un órgano emisor de estímulos y de percepción sensorial (Saini et al., 2010), que incluso desde una arista psicosexual, de acuerdo con Cortés (2010) deja ver como la boca se encuentra cargada de libido, que moviliza la pulsión del sujeto, hacia la succión como práctica erótica.

Aunque, lo que se persigue con la práctica del sexo oral y en ocasiones ingesta del semen, es la satisfacción o el alcance del placer sexual, no se debe olvidar que la cercanía del otro tiene condiciones de aproximación que pueden dar lugar a, que tan solo me interese un parte de él, mientras el resto es vaciado (Fernández-Chico, 2009). Situación, que reduce la vida humana y sus miembros a simples objetos y fragmentos de memorias vividas, en cuyo horizonte si bien está el divertirse, entendido como "[...] la satisfacción de consumir y asimilar artículos, espectáculos, comida, bebidas, cigarrillos, gente, conferencias, libros, peliculas; todo se consume, se traga" (Fromm, 2003, p. 111), no cierra la posibilidad para desarrollar cierta sensibilidad práctica y polifórmica desde el individuo, para favorecer una interacción sociosexual responsable. Los trayectos biográficos con respecto al placer, no solo fluyen ahora entre lo íntimo, semipúblico y público de sus manifestaciones, sino que además, deben atender a nuevos eventos, procesos y aprendizajes como producto del devenir de los tiempos y la presencia efectiva de la muerte-enfermedad en cada escenario vital, lo que hace imperativo actuar con prevención.

Prevenir significa anticiparse en el tiempo para visualizar el futuro, desde la racionalización del deseo, en pro de pensar comportamientos de prevención frente a la ejecución de prácticas sexuales peligrosas, que a la fecha se ofrecen como líneas de fuga que surgen dentro del orden social y son esbozadas tanto por individuos o grupos sociales, en calidad de ejecutores de la práctica del sexo oral, pero que dejan ver como el uso condón podría reducir la exposición a ITS orales y/o genitales derivadas de los fluidos presentes en la actividad sexual penetrativa. El placer sensual o erótico que desencadena la práctica del sexo oral, constituye una experiencia corporal surgida a partir de una fantasía sexual, cuya referencia se ubica a través de diferentes procesos históricos y representaciones socioculturales, en torno a los sujetos/objetos de deseos y fronteras normativas establecidas para el ejercicio de la sexualidad. Un círculo tan placentero como peligroso.

\section{Coda}

El presente ejercicio de reflexión, frente al placer del cuerpo en la práctica del sexo oral entre HSH, busco dar cuenta no solo de sus posibilidades como factor de riesgo individual y colectivo, sino también como elemento 
configurador de unas relaciones de poder asimétricas y de constitución de subjetividades subordinadas a las representaciones de género (masculino) y estereotipos sexuales contenidas en el acto, o gestadas mediante el establecimiento de negociaciones que buscan asegurar el goce corporal y mantenimiento del deseo como condición objetiva en tales sujetos. Validando así la idea de Rolnik y Guattari (2006) que el deseo tiene que ver con "todas las formas de voluntad de vivir, de crear, de amar; a la voluntad de inventar otra sociedad, otra percepción del mundo, otros sistemas de valores" (p. 254). El deseo, denota autoconocimiento y búsqueda de correspondencia consigo mismo, a partir de una organización del cuerpo, para comunicar la producción de "algo" y precisar así de un momento de visibilidad que permita a los sujetos su identificación.

Ante el incremento de las ITS y la violencia contra este colectivo social, se hace necesario fortalecer las estrategias gubernamentales en salud sexual y reproductiva, además de activar la acción social para proteger sus vidas liberándolos del miedo o la exclusión. Si bien es cierto, el sexo oral, constituye una experiencia cargada de valor cultural y pautas de proximidad corporal, orientada a satisfacer las demandas individuales de goce, no se debe olvidar que este tipo de práctica sexual se ve transversalizada por actitudes y hábitos personales que contrastan con elementos del contexto social estereotipos de género y conocimientos frente a la sexualidad- que pueden llegar en ocasiones a generar etiquetamientos como producto del estigma.

Al hablar de los HSH y de las distintas prácticas sexuales penetrativas no protegidas que ejecutan (pene-boca, pene-ano), es posible advertir que tales experiencias se anclan a aspectos como belleza, posición social y carácter masculino de quien será el compañero sexual, elementos que configuran una realidad en donde el vivir la sexualidad de forma segura se transforma en un desafío individual, colectivo y también institucional, ante la erotización del riesgo que traen las prácticas sexuales no protegidas y espontáneas.

\section{Referencias Bibliográficas}

Barreda, V. y Isnardi, V. (2006). Travestis y prevención del vih/sida: un escenario de categoría en crisis. En Cáceres, C. et al. (eds.) Sexualidad, estigma y derechos humanos. Desafíos para el acceso a la salud en América Latina. (pp.167-176). Lima: FASPA/UPCH.

Bruckner, P. y Finkielkraut, A. (2019). El nuevo desorden amoroso. Barcelona: Anagrama.

Cabra-Ayala, N. A. (2017). La herida masculina. Nómadas, 46, 167-81. http://www.scielo.org.co/pdf/noma/n46/0121-7550-noma-46-00167.pdf

Cardona, J.F., Hernández J.C., Suárez, G.R., Zapata, W. (2015). Conocimientos, actitudes y prácticas sobre vih/sida en estudiantes de educación media de Medellín. Archivos de Medicina. 11, 4-10:1-10. doi: 10.3823/1272 
Carmona-Lorduy, M., Porto-Puerta, I., Lanfranch, H., Medina-Carmona, W., Werner, L., Maturana, S. (2018). Manifestaciones bucales de enfermedades de transmisión sexual identificadas en tres servicios de estomatología en Sur América. Univ. Salud. 20(1), 82-88. http://dx.doi.org/10.22267/rus.182001.112

Cortés, A., Sordo, M., Cumbá, C., García, R., Fuentes, J. (2000). Comportamiento sexual y enfermedades de transmisión sexual en adolescentes de secundaria básica de ciudad de La Habana. Revista Cubana de Higiene y Epidemiologia.38(1), 5359.

Cortés, N. (2010). La succión: una actividad erótica. Revista Facultad de Odontología Universidad Antioquía. 11: 47-50.

Deleuze, G. (1995). Deseo y placer. Archipiélago. Cuadernos de Crítica de la Cultura (23), 3-17. http://www.medicinayarte.com/librosdigitales/oficina/biblioteca/gd_deseo_y_placer.pdf

Deleuze, G. (1996). Spinoza y el problema de la expresión. Barcelona: Muchnik

Epicuro. (1997). Carta a Meneceo. En: Sobre la felicidad (págs. 23-29). Santafé de Bogotá: Norma.

Estrada, J.H., Vargas-Rico, L. (2011). Invisibles y excluidos: la infección VIH/SIDA entre hombres que tienen sexo con hombres (HSH). En: Arrivillaga, M., y Useche, B. (Dirs). Sida y sociedad: crítica y desafíos sociales frente a la epidemia (pág. 115-169). Colombia: Gente Nueva Editorial.

Fallaci, O. (1996). Un hombre. Barcelona: Editorial Noguer.

Fernández- Chico, J. M. (2009). El amor a Žižek. Un acercamiento al amor desde la noción de Slavoj Žižek. Sociogénesis, Revista Electrónica de Sociología, (2). 214 https://cdigital.uv.mx/bitstream/handle/123456789/9619/ar2_juldic2009.pdf? sequence $=2 \&$ is Allowed $=y$

Foucault, M. (2007/1976). Historia de la sexualidad. Volumen. I. La voluntad de saber. $31^{\circ}$ ed. México: Siglo XXI.

Fromm, E. (2003). El arte de amar. Una investigación sobre la naturaleza del amor. Barcelona: Paidós

Grossberg, L. (2003). Identidades y estudios culturales. ¿No hay más qué eso? En Hall, S. y Dugay, P. (comps). Cuestiones e Identidad Cultural (pág. 148-180). Madrid: Amorrortu.

Grupo de Trabajo sobre Tratamientos del VIH de Cataluña (S.f). infovihtal \#15 sexo oral. http://gtt-vih.org/files/active/0/InfoV_esp_15.pdf

Hinojos-Armendáriz, D. A., Palma-Cano, L. E., Moreno-Brito, V., Licón-Trillo, A., Lora-Orduo, N. A., Carrera-Chávez, N. N., Santana-Rodríguez, V. M., DuqueRodríguez, J. \& Leal-Berumen, I. (2016). Prevalencia de tipos de virus del 
papiloma humano en hombres que tienen sexo con hombres, en Chihuahua, México. Acta Universitaria, 26(5), 62-69. doi: 10.15174/au.2016.1156

Lewis, M. A., Granato, H., Blayney, J. A., Lostutter, T. W. \& Kilmer, J. R. (2011). Predictors of hooking up sexual behaviors and emotional reactions among U.S. College Students. Arch Sex Behav. 41 (5),1219-1229. doi: 10.1007/ s10508-0119817-2

Marín-Posada, S., y Posada-Zapata, M.C. (2020). Menosprecio y riesgo en hombres que tienen sexo con hombres viviendo con VIH en Medellín. Promoc. Salud. 25 (1), 13-28. DOI:10.17151/hpsal.2020.25.1.2

Mecanismo de Coordinación de País - MCP Colombia Fondo Mundial de Lucha Contra el Sida, la Tuberculosis y la Malaria. (2016). Informe de resultados. Comportamiento sexual y prevalencia de VIH hombres que tienen relaciones sexuales con otros hombres en siete ciudades de Colombia (Bogotá, Medellín, Cali, Barranquilla, Cúcuta, Pereira y Cartagena). https://www.minsalud.gov.co/sites/rid/Lists/BibliotecaDigital/RIDE/INEC/INT OR/libro-comportamiento-sexual-hombres-2016.pdf [consultado 2019 jun 29].

Moller-González, N. (2013). Dentro de ella: Representación científica y placer sexual. Nómadas 38, 49-63. http://www.scielo.org.co/pdf/noma/n38/n38a04.pdf

ONUSIDA (2017). Estadísticas mundiales sobre el VIH de 2017. [Internet] [consultado 2019 jun 29]. https://www.unaids.org/es/resources/fact-sheet

Nieto, T., Larrea, S., Moreno, G., Pinto, M., Iturralde, P. (2012). Infecciones de transmisión sexual, prevalencia de VIH/SIDA sífilis, en estudiantes adolescentes de 5 y 6 tos cursos, encuesta de conocimientos, actitudes y practicas (CAP) en el Cantón Ibarra. Revista Científica y Tecnológica "El Investigador". (4), 60-69.

Perlongher, N. (1993). La prostitución masculina. Buenos Aires: La Urraca.

Philpott, A., Knerr, W., y Boydell., V. (2006). El placer y la prevención: cuando el buen sexo es un sexo más seguro. Reproductive Health Matters, 14 (28),16-24.

Ramírez-García, V. H. (2017). Hola, ¿Cogemos? Economía del deseo y capital erótico en sitios de encuentro en internet. Interdisciplina 5 (11), 79-108. http://dx.doi.org/10.22201/ceiich.24485705e.2017.11.61326

Rolnik, S., Y Guattari, F. (2006). Micropolítica. Cartografías del deseo. Madrid: Editorial Traficantes de Sueños.

Saini, R., Saini, S, Sharma, S. (2010). Oral sex, oral health and orogenital infections. J Global Infect Dis. 2, 57-62

Sanabria-S., F. (2010). Los no-lugares del amor en la ciudad: Una aproximación etnográfica a las salas X de Medellín. Boletín de Antropología, 18(35), 116-131. https://revistas.udea.edu.co/index.php/boletin/article/view/6958 
Suárez, R., Niño, N., Sepúlveda, R y Vesga, J.C. (2008). Contextos socioculturales de riesgo para contraer VIH en Cartagena. Antípoda 6, 313-330. http://www.scielo.org.co/pdf/antpo/n6/n6a16.pdf

Tiefer, E. (1995). El sexo no es un acto natural. 1 ed. Madrid: Talasa.

Viscarra, A. T., Brebi, M. P., Andana, V. A. \& Sánchez, G. R. (2013). Infecciones de transmisión sexual en semen. El hombre como vector de transmisión. Int. J. Morphol., 31(1), 254-263. http://dx.doi.org/10.4067/S0717-95022013000100041 